\title{
Association between maternal depression and wheezing in preschool children
}

\author{
Şebnem Özdoğan¹, Tuğçe Kurtaraner², Haşim Gencer, Dilek Kabakc1-Kaya², Selime \\ Çelik-Erden ${ }^{4}$ \\ Departments of ${ }^{1}$ Pediatric Pulmonology, ${ }^{2}$ Pediatrics, and ${ }^{4}$ Psychiatry, Şişli Hamidiye Etfal Research and Training Hospital, \\ ${ }^{3}$ Department of Pediatrics, Esenler Women's and Children's Hospital, Istanbul, Turkey. \\ Email: ozdogan65@hotmail.com \\ Received: 10th October 2016, Revised: 23rd December 2016, Accepted: 1st March 2017
}

SUMMARY: Özdoğan Ş, Kurtaraner T, Gencer H, Kabakc1-Kaya D, Çelik- Erden S. Association between maternal depression and wheezing in preschool children. Turk J Pediatr 2016; 58: 632-640.

The aim of this study was to assess whether maternal depression was associated with recurrent wheezing attacks in preschool children. A case-control study was conducted involving 51 preschool children who were hospitalized due to wheezing attacks and 50 age-matched healthy subjects. Sociodemographic characteristics of the children and their mothers were investigated. The Beck depression inventory was administered to the mothers. In the case group, the anthropometric measurements were determined to be significantly lower than in the control group $(\mathrm{p}<0.05)$. The rate and severity of maternal depression were significantly higher $(\mathrm{p}<0.05)$ in mothers of cases. Multivariate regression analysis indicated that male gender of the child and maternal history of asthma were significant risk factors for maternal depression (odds ratio 4.671; 95\% CI 1.21-18.11 and 5.263, 95\% CI 1.05-32.42, respectively). Having a male child with wheezing attacks and a history of maternal asthma were identified as important risk factors for maternal depression.

Key words: maternal depression, wheezing, preschool children.

The prevalence of recurrent wheezing attacks in preschool children has been increasing over the past 10 years ${ }^{1}$. Wheezing attacks are stressful not only for children but also for their families. Previous studies have suggested that caring for a child with wheezing attacks affects maternal mental health and maternal mental health impacts a child's wheezing attacks ${ }^{2,3}$. Another report suggested that due to the inadequate assessment and follow-up of children whose parents have impaired mental health and insufficient compliance with treatment, treatment remains ineffective, rates of hospitalization are high and quality of life is low in children with wheezing attacks ${ }^{4-6}$. It has also been claimed that parental stress could cause wheezing attacks during early childhood7

Studies have shown that psychologic stress increases respiratory tract infections, thereby affecting wheezing attacks in children ${ }^{8}$. The hypothesis that stress suppresses host defense mechanisms against infectious diseases has been supported by studies describing associations between stress and influenza $\mathrm{A}^{9}$ and the common cold ${ }^{10}$. Additionally, studies have shown that children whose parents have been exposed to stress suffer from viral respiratory infections ${ }^{11,12}$.

In one study, cases whose mothers had depression were followed from birth to 7 years of age ${ }^{13}$. This study claimed that these children had a higher risk of asthma and suggested that their mother's condition increased the child's somatic sensitivity and caused wheezing and asthma. It has also been hypothesized that a mother's mental disorder may lead to inadequate treatment of their child's asthma and, due to their child's early exposure to stress, affect the hypothalamic pituitary axis (HPA) and sympathetic adrenal axes, thereby leading to dysregulation of the immune system and setting the basis for asthma development ${ }^{14}$. It is of vital importance to identify maternal depression and take appropriate measures to optimize 
the care of children with wheezing attacks by enabling them to avoid wheezing attacks and easily adapt to treatment modifications.

In this study, we aimed to assess whether maternal psychological status was associated with recurrent wheezing attacks in preschool children who had been hospitalized due to recurrent wheezing attacks.

\section{Material and Methods}

\section{Patients and Controls}

This study was designed as a case-control study. The case group consisted of children below 5 years of age who were hospitalized due to wheezing attacks and their mothers. Patients with underlying chronic diseases such as cystic fibrosis, tuberculosis, ciliary dyskinesia, congenital airway anomalies, immunodeficiency disorders and cardiac disease causing recurrent wheezing attacks were excluded. The control group consisted of healthy children below 5 years of age who were seen at the pediatrics outpatient clinic and their mothers. After obtaining written consent from all participating mothers, 2 groups of mothers were asked to complete 2 different forms of the survey. Using the standardized survey form, mothers of cases were questioned about the clinical features of and potential risk factors for the wheezing attacks and their sociodemographic characteristics. Afterwards, the mothers were provided the short Beck depression inventory, which investigates depression symptoms, to fill out on their own. In order to eliminate the maternal anxiety due to a hospitalized child, the survey and Beck depression inventory were provided to the mothers of hospitalized children at discharge. The principal investigator read the questions to illiterate mothers.

\section{Beck Depression Inventory (BDI)}

One of the most frequently used self-report questionnaires in research, the BDI, was used to comprehensively detect depression symptoms. The cognitive aspect of depression was also evaluated. In a Turkish adaptation study conducted with university students, a cut-off score of 17 was reported to correctly identify $90 \%$ of depression cases $^{15}$.

The BDI consists of 21 items that are used to assess the respondent's mental status. Each item describes a manifestation of depression. For each item, there are 4 choices indicating varying levels of depression intensity. The mothers were asked to carefully read these choices and select the choice that was the most accurate representation of their condition, taking into consideration their mental status within the past week. The 4 different responses choices for each item corresponded to scores between 0 and 3 . The total score for the index ranged between 0 and 63. Scores of 0-11 was described as normal. Scores of 1116 indicated mild mood disturbance. Scores of 17-20 indicated borderline clinical depression. Scores of 21-30 indicated moderate depression. Scores of 31-40 indicated severe depression, and scores of 41 and higher indicated very severe depression. Cases with a total score $\geq 17$, considered to be consistent with depression, were advised to see a psychiatrist. Mothers who were willing to seek counseling had a session with a psychiatrist. The study was approved by the Şişli Hamidiye Etfal Research and Training Hospital's ethics committee.

\section{Statistical Analysis}

NCSS (Number Cruncher Statistical System) 2007 (Kaysville, Utah, USA) software was used for statistical analyses. To assess study data and generate descriptive statistics, comparisons of continuous data (mean, standard deviation, median, frequency, ratio, minimum, maximum) were performed using Student's t tests for parameters with normal distributions and Mann-Whitney U-tests for parameters without normal distributions. For comparisons of categorical data, Pearson's chi-square, FisherFreeman-Halton, Fisher's exact and Yates' continuity correction (Yates' corrected chisquare) tests were used. For multivariate evaluations, logistic regression analysis was used. Significance was set at $\mathrm{p} \leq 0.05$.

\section{Results}

The study was conducted with 101 cases in total, including 51 cases and 51 controls. Table I presents comparisons of children's demographic features between the case and control groups. There were no significant differences between the case and control groups in gender, age or mode of delivery. The anthropometric measurements of children in the case group (height, height percentile, weight, weight percentile) were significantly lower than were those of control children $(p=0.005$, $0.004,0.001$ and 0.003 , respectively). When 
Table I. Demographic Characteristics of the Study Population of Children in the Case-Control Study (n: 101).

\begin{tabular}{|c|c|c|c|c|}
\hline & & Control (n: 50) & Cases (n: 51) & p \\
\hline \multirow[t]{2}{*}{ Gender, n (\%) } & Male & $31(62.0)$ & $31(60.8)$ & \multirow[t]{2}{*}{ a 1.000} \\
\hline & Female & $19(38.0)$ & $20(39.2)$ & \\
\hline \multirow[t]{2}{*}{ Age (months) } & Mean \pm SD & $21.22 \pm 14.38$ & $16.82 \pm 12.10$ & \multirow[t]{2}{*}{ b0.140 } \\
\hline & Range (median) & $2-56(75.0)$ & $3-50(13)$ & \\
\hline \multirow[t]{2}{*}{ Height $(\mathrm{cm})$} & Mean \pm SD & $82.01 \pm 14.64$ & $74.43 \pm 11.41$ & \multirow[t]{2}{*}{${ }^{c} 0.005$} \\
\hline & Range (median) & $57-112(81.5)$ & $53-100(73)$ & \\
\hline \multirow{3}{*}{$\begin{array}{l}\text { Height percentile, } \\
\text { n }(\%)\end{array}$} & $<3 p$ & $6(12.0)$ & $18(35.3)$ & \multirow[t]{3}{*}{$\mathrm{d} 0.004$} \\
\hline & Normal & $41(82.0)$ & $33(64.7)$ & \\
\hline & $>95 p$ & $3(6.0)$ & $0(0.0)$ & \\
\hline \multirow[t]{2}{*}{ Weight (kg) } & Mean \pm SD & $11.49 \pm 3.53$ & $9.16 \pm 3.05$ & \multirow[t]{2}{*}{${ }^{c} 0.001$} \\
\hline & Range (median) & $5.2-20(11)$ & $3.1-16.5(9)$ & \\
\hline \multirow{3}{*}{$\begin{array}{l}\text { Weight } \\
\text { percentile, } \\
\mathrm{n}(\%)\end{array}$} & $<3 p$ & $6(12.0)$ & $20(39.2)$ & \multirow[t]{3}{*}{ d0.003 } \\
\hline & Normal & $42(84.0)$ & $30(58.8)$ & \\
\hline & $>95 p$ & $2(4.0)$ & $1(2.0)$ & \\
\hline \multirow{2}{*}{$\begin{array}{l}\text { Birth weight } \\
\text { (gram) }\end{array}$} & Mean \pm SD & $3,253.60 \pm 383.37$ & $2,673.52 \pm 960.31$ & \multirow[t]{2}{*}{ b0.008 } \\
\hline & Range (median) & $2,470-4,600(3,200)$ & $650-4,110(2,800)$ & \\
\hline \multirow{2}{*}{$\begin{array}{l}\text { Gestational age, } \\
\mathrm{n}(\%)\end{array}$} & Term & $50(100.0)$ & $38(74.5)$ & \multirow[t]{2}{*}{ d0.001 } \\
\hline & Preterm & $0(0.0)$ & $13(25.5)$ & \\
\hline \multirow{2}{*}{$\begin{array}{l}\text { Mode of delivery, } \\
\text { n (\%) }\end{array}$} & NSVD & $25(50.0)$ & $21(41.2)$ & \multirow[t]{2}{*}{${ }^{\mathrm{a}} 0.490$} \\
\hline & Cesarean section & $25(50.0)$ & $30(58.8)$ & \\
\hline
\end{tabular}

aYates continuity correction test; ${ }^{\mathrm{b}}$ Mann-Whitney U-test; 'Student $\mathrm{t}$ test; ${ }^{\mathrm{d}}$ Fisher-Freeman test

NSVD: normal spontaneous vaginal delivery; SD: standard deviation

birth weights were compared, we detected a significantly lower birth weight in the case group than in the control group $(\mathrm{p}=0.008)$. Similarly, children in the case group had been born preterm at a significantly higher rate than control children were $(p=0.001)$.

Sociodemographic characteristics of the case and control group families are presented in Table II. Comparisons of cases and controls revealed no significant differences in maternal age, working status, smoking, paternal age, or history of asthma between the two groups ( $p>0.050$ ). Assessment of maternal educational status showed that mothers in the case group were illiterate at a significantly higher rate than control mothers were $(p=0.050)$. A history of maternal asthma was detected significantly more frequently in the case group relative to the control group $(p=0.027)$. A comparison of household income revealed that the income of case group families was significantly lower than that of control group families $(p=0.002)$. Number of people in the household, number of siblings and sibling history of asthma were significantly higher in the case group than in the control group $(\mathrm{p}=0.001,0.011$ and 0.034 , respectively).

The distribution of diseases in the case group is presented in Table III. Twenty-seven (52.9\%) of the recurrent wheezing attack cases had a history of neonatal intensive care stay. There were 15 (29.4\%) cases diagnosed with bronchopulmonary dysplasia (BPD), and 14 $(27.5 \%)$ cases had received treatment for gastroesophageal reflux (GER). While the median number of wheezing attacks was 13 (range: $3-40$ ), the median number of hospitalizations was 3 (range: 1-25). Of the cases, $8(15.7 \%)$ had not previously received nebulizer therapy at home; $22(43.1 \%)$ received nebulizer therapy as needed, and $21(41.2 \%)$ cases received daily nebulizer treatment. Of 
Table II. Family History of Children in the Case-Control Study.

\begin{tabular}{|c|c|c|c|c|}
\hline & & Control (n: 50) & Cases (n: 51) & $\mathrm{p}$ \\
\hline \multirow[t]{2}{*}{ Mother's age (years) } & Mean \pm SD & $28.62 \pm 4.55$ & $29.11 \pm 5.59$ & ${ }^{\circ} 0.625$ \\
\hline & Range (median) & $18-40(28)$ & $18-41(28)$ & \\
\hline \multirow{2}{*}{$\begin{array}{l}\text { Mother's working } \\
\text { status, n (\%) }\end{array}$} & Employed & $3(6.0)$ & $2(3.9)$ & $\mathrm{e} 0.678$ \\
\hline & Unemployed & $47(94.0)$ & $49(96.1)$ & \\
\hline \multirow{4}{*}{$\begin{array}{l}\text { Mother's educational } \\
\text { status, n (\%) }\end{array}$} & Illiterate & $1(2.0)$ & $8(15.7)$ & d 0.050 \\
\hline & Elementary school & $19(38.0)$ & $20(39.2)$ & \\
\hline & Middle-high school & $26(52.0)$ & $22(43.1)$ & \\
\hline & University & $4(8.0)$ & $1(2.0)$ & \\
\hline $\begin{array}{l}\text { Maternal smoking, } \mathrm{n} \\
(\%)\end{array}$ & Yes & $7(14.0)$ & $10(19.6)$ & ${ }^{\mathrm{a}} 0.626$ \\
\hline \multirow[t]{2}{*}{ Father's age (year) } & Mean \pm SD & $31.94 \pm 4.84$ & $33.56 \pm 6.30$ & ${ }^{\circ} 0.148$ \\
\hline & Range (median) & $19-43(31.5)$ & $22-49(32)$ & \\
\hline $\begin{array}{l}\text { Maternal asthma, } \mathrm{n} \\
(\%)\end{array}$ & Yes & $0(0.0)$ & $6(11.8)$ & e 0.027 \\
\hline \multirow{2}{*}{$\begin{array}{l}\text { Father's working } \\
\text { status, n (\%) }\end{array}$} & Employed & $50(100.0)$ & $50(98.0)$ & $\mathrm{e} 1.000$ \\
\hline & Unemployed & $0(0.0)$ & $1(2.0)$ & \\
\hline Paternal asthma, n(\%) & Yes & $0(0.0)$ & $2(3.9)$ & e 0.495 \\
\hline \multirow{2}{*}{$\begin{array}{l}\text { Household income } \\
\text { (TL) }\end{array}$} & Mean \pm SD & $1,893.0 \pm 730.80$ & $1,586.27 \pm 915.64$ & b0.002 \\
\hline & Range (median) & $1,000-4,000(1,700)$ & $700-5,000(1,500)$ & \\
\hline \multirow[t]{4}{*}{ Family size, n (\%) } & 3 person & $14(28.0)$ & $4(7.8)$ & ${ }^{\mathrm{a}} 0.001$ \\
\hline & 4 person & $26(52.0)$ & $14(27.5)$ & \\
\hline & 5 person & $5(10.0)$ & $12(23.5)$ & \\
\hline & $\geq 6$ person & $5(10.0)$ & $21(41.2)$ & \\
\hline \multirow{3}{*}{$\begin{array}{l}\text { Number of siblings, } \\
\text { n (\%) }\end{array}$} & None & $18(36.0)$ & $9(17.6)$ & $\mathrm{g} 0.011$ \\
\hline & 1 sibling & $24(48.0)$ & $21(41.2)$ & \\
\hline & $\geq 2$ siblings & $8(16.0)$ & $21(41.2)$ & \\
\hline $\begin{array}{l}\text { Asthma in siblings, } \\
\mathrm{n}(\%)\end{array}$ & Yes & $2(4.0)$ & $10(19.6)$ & ${ }^{\mathrm{a}} 0.034$ \\
\hline $\begin{array}{l}\text { YYates continuity corre } \\
\text { dFisher-Freeman test }\end{array}$ & & $\begin{array}{l}\text { n-Whitney U-test } \\
\text { er's Exact test }\end{array}$ & $\begin{array}{c}\text { cStudent } \mathrm{t} \text { test } \\
\text { arson Chi squared test }\end{array}$ & \\
\hline
\end{tabular}

the cases receiving nebulizer therapy, 3 (5.9\%) had received only inhaled salbutamol, 38 $(74.5 \%)$ had received salbutamol + inhaled corticosteroids (ICS), and 2 (3.9\%) had received salbutamol, ICS and montelukast.

Table IV presents the Beck inventory scores of the mothers. The mean depression score in the case group was $15.21 \pm 8.49$, which was significantly higher than the mean depression score in the control group $(p=0.001)$. The severity of depression significantly differed between the groups, which resulted from differences in the rates of moderate depression $(p=0.001)$.
Depression risk factors were investigated in mothers of cases who were admitted due to wheezing attacks (Table V). Having a child of male gender (odds ratio 4.857; 95\% CI 1.3217.899) and maternal history of asthma (odds risk 5.60; 95\% CI 1.01-31.24) were significantly associated with maternal depression in the univariate analyses. The impact of a history of intensive care stay, nebulizer treatment, GER diagnosis, number of wheezing attacks, sibling history of asthma, maternal smoking, number of hospitalizations due to wheezing attacks and BPD diagnosis on maternal depression were not found to be statistically significant 
Table III. Clinical Features of Children with Recurrent Wheezing (n: 51).

\begin{tabular}{llll}
\hline Clinical Features & & N & $\%$ \\
\hline NICU stay & & 27 & 52.9 \\
BPD & None & 15 & 29.4 \\
Nebulizer therapy & Salbutamol & 8 & 15.7 \\
& ICS & 3 & 5.9 \\
& ICS + montelukast & 2 & 74.5 \\
How often taking nebule therapy? & None & 8 & 3.9 \\
& As needed & 22 & 15.7 \\
GER therapy & Daily & 21 & 43.1 \\
Number of wheezing attacks, median (range) & 14 & 27.5 \\
Number of hospitalization, median (range) & & $13(3-40)$ & \\
\hline BPD bron & & $3(11-25)$ & \\
\hline
\end{tabular}

BPD: bronchopulmonary dysplasia; GER: gastroesophageal reflux; ICS: inhaled corticosteroid therapy; NICU: neonatal intensive care unit

( $p>0.05)$. We evaluated the variables whose association with maternal depression in the univariate models was deemed significant or close to significant using multivariate logistic regression analysis. The resultant model was found statistically significant and explained $74.5 \%$ of the variation in maternal depression $(\mathrm{F}=10.086 ; \mathrm{p}=0.006)$. Similarly, male gender of the child and history of maternal asthma were significant in the multivariate model. Thus, male gender and maternal asthma were risk factors that were significantly associated with maternal depression (odds ratio 4.671; 95\% CI 1.21-18.11; odds ratio 5.263; $95 \%$ CI 1.05-32.42, respectively).

\section{Discussion}

Based on our results, anthropometric measures, preterm status and socioeconomic factors differed significantly between preschool children who were hospitalized due to recurrent wheezing attacks and age-matched controls. The incidence and severity of depression were detected to be significantly high in mothers of children with wheezing attacks than mothers of control children. Investigation of risk factors for maternal depression showed that male gender of the child and history of maternal asthma were significant risk factors.

In line with the literature, we detected that anthropometric values and family socioeconomic level were significantly lower and that history of maternal asthma, rate of parental illiteracy, number of people living in the household, sibling history of asthma and rate of preterm birth were significantly higher in preschool children who were hospitalized due to recurrent wheezing attacks relative to control children ${ }^{16-20}$. In contrast to some studies, no correlation was identified between maternal smoking and wheezing attacks ${ }^{21,22}$.

Since mothers are more actively involved in childcare, they are exposed to greater levels of stress than fathers are. Thus, anxiety and depression are reported at higher rates in mothers ${ }^{23,24}$. The mother-child relationship may be very important to mental health since they affect each other in a reciprocal fashion. Thus, maternal psychological distress affects the physical and psychological health of the child and vice versa ${ }^{25}$. Due to the design of the studies, it is not known whether maternal mental health issues lead to wheezing attacks during early childhood by affecting stress responses in children or if wheezing attacks in children lead to maternal anxiety and depression. In our study, we detected a significant association between recurrent wheezing attacks and maternal depression; however, we cannot explain whether the wheezing attacks increased the tendency toward depression in mothers or recurrent wheezing attacks occurred in children as a result of maternal depression because we did not assess 
Table IV. Maternal Depression in the Study Population.

\begin{tabular}{|c|c|c|c|c|}
\hline & & Control (n: 50) & Cases (n: 51) & $\mathrm{p}$ \\
\hline \multirow[t]{2}{*}{ Depression score } & Mean \pm SD & $8.42 \pm 3.72$ & $15.21 \pm 8.49$ & b0.001 \\
\hline & Range (median) & $1-17(8)$ & $1-40(15)$ & \\
\hline \multirow[t]{2}{*}{ Maternal depression, $\mathrm{n}(\%)$} & Yes & $2(4.0)$ & $21(41.2)$ & ${ }^{\mathrm{a}} 0.001$ \\
\hline & No & $48(96.0)$ & $30(58.8)$ & \\
\hline \multirow[t]{5}{*}{ Severity of depression, $\mathrm{n}(\%)$} & Normal & $36(72.0)$ & $16(31.4)$ & ${ }^{c} 0.001$ \\
\hline & $\begin{array}{l}\text { Mild mood } \\
\text { disturbance }\end{array}$ & $12(24.0)$ & $14(27.5)$ & \\
\hline & $\begin{array}{l}\text { Borderline clinical } \\
\text { depression }\end{array}$ & $2(4.0)$ & $8(15.7)$ & \\
\hline & Moderate & $0(0.0)$ & $10(19.6)$ & \\
\hline & Severe & $0(0.0)$ & $3(5.9)$ & \\
\hline
\end{tabular}

aYates continuity correction test; ${ }^{\mathrm{b}}$ Mann-Whitney U-test; ${ }^{\mathrm{c}}$ Fisher-Freeman test; SD: standard deviation

prenatal maternal depression.

A previous study including in 490 families in the USA suggested that familial stress was associated with wheezing in children ${ }^{26}$. However, a study conducted in Sweden that included 97 families suggested that wheezing in children resulted from dysfunctional family interactions ${ }^{27}$.

Maternal anxiety and depression during pregnancy, the postpartum period and thereafter have been found to be associated with wheezing and asthma ${ }^{28-33}$. A meta-analysis of 10 studies showed that prenatal psychological stress was associated with wheezing, asthma and other respiratory complaints ${ }^{34}$.

Lefevre et al. reported a significant relation between mother's depressive symptoms according to the Beck inventory and infant's wheezing severity among the cases ${ }^{28}$. The more the mother was depressed, the more the infant's asthma was severe (OR 4.25, 95\% CI $1.14,15.9$ between severe infant's wheezing and severe maternal depression). In our study, we found significant association between mother's depressive symptoms and recurrent wheezing in preschool children, however we did not investigate the relations between mother's depressive symptoms and wheezing severity among the cases.

Maternal depression risk factors have been found to include having small children, living in the suburbs and associated low socioeconomic conditions, poverty, limited activity and health issues ${ }^{35}$. Additionally, having small children, anxiety, health issues, worries over being a parent, and low levels of emotional support and training have been found to be risk factors for persistent depression ${ }^{36}$. In our study, male gender of the child and maternal asthma history were determined to be important risk factors for maternal depression. Similarly, in a longterm trial in Australia, an investigation of risk factors for asthma in children approximately 6 to 7 years of age with and without wheezing revealed that maternal depression and maternal asthma were significant risk factors ${ }^{13}$. Previous studies suggest that male sex is linked to slower maturation rates in early life, which may create a longer period of early vulnerability to caregiving risks such as maternal depression for boys versus girls ${ }^{37,38}$. However, the mechanisms underlying these associations remain unclear.

While a few studies have reported that behavioral treatment increases asthma control in adults ${ }^{39}$ and children ${ }^{40}$, a study on the effect of maternal depression treatment on asthma control in children by Perry et al. ${ }^{41}$ showed that maternal depression treatment was more effective for asthma control than asthma treatment and resulted in reduced asthma-related costs.

The factors limiting this study include the absence of breastfeeding history, atopy investigation, and psychological status assessment, and small sample size. We should consider maternal anxiety due to a hospitalized child although the BDI were provided to 
Table V. Risk Factors Related to Maternal Depression in Children with Recurrent Wheezing.

\begin{tabular}{lccccccc}
\hline \multirow{2}{*}{ Cases (n: 51) } & \multicolumn{3}{c}{ Univariate regression } & analysis & & \multicolumn{3}{c}{ Multivariate regression analysis } \\
\cline { 2 - 3 } \cline { 7 - 8 } & $\mathrm{p}$ & OR & \%95 CI & & $\mathrm{p}$ & OR & \%95 CI \\
\hline Gender (male) & 0.029 & 4.857 & $1.32-17.89$ & & 0.026 & 4.671 & $1.21-18.11$ \\
NICU stay & 0.431 & 1.857 & $0.60-5.78$ & & & \\
Nebulizer therapy & 0.445 & 2.375 & $0.43-13.13$ & & 0.596 & 1.723 & $0.23-12.86$ \\
GER therapy & 0.639 & 1.643 & $0.48-5.68$ & & & \\
Number of wheezing & 0.126 & 1.045 & $0.99-10.11$ & 0.501 & 1.025 & $0.95-1.10$ \\
attacks & 0.050 & 5.600 & $1.01-31.24$ & 0.043 & 5.263 & $1.05-32.42$ \\
Maternal asthma & 0.785 & 1.563 & $0.39-6.27$ & & & \\
Asthma in siblings & 1.000 & 0.941 & $0.23-3.85$ & & & \\
Maternal smoking & 0.222 & 1.093 & $0.95-1.26$ & 0.317 & 1.090 & $0.92-1.29$ \\
Hospital stay & 0.870 & 1.375 & $0.41-4.64$ & & & \\
BPD & & &
\end{tabular}

BPD: bronchopulmonary dysplasia; CI: confidence interval; GER: gastroesophageal reflux; NICU: neonatal intensive care unit; OR: Odds ratio

the mothers of the hospitalized children at discharge. A strength of this study is that many confounders that could affect maternal depression were considered.

In conclusion, depression was detected to be significantly higher in mothers of preschool children who were admitted due to recurrent wheezing attacks than mothers of control children; male gender of the child and maternal asthma history were determined to be important risk factors. However, future longitudinal studies are needed to determine whether there is a causal link between maternal depression and asthma in preschool children and which proportion of preschool children with wheezing illness will become asthmatics. A previous study suggested that pediatricians failed to identify most depressive symptoms in mothers ${ }^{42}$. Therefore, during the monitoring of children with chronic disorders, such as recurrent wheezing attacks and asthma, direct questions regarding the mothers' mental status should be asked to increase awareness related to this topic. Mental health surveillance and early diagnosis of and enhanced primary support for women may be effective in reducing asthma and psychobiological risks associated with other non-communicable chronic diseases. Provision of access to mental and social support to women and children at critical times would increase their quality of life and, thus, the wellness and quality of life of the society at large.

\section{Acknowledgements}

We wish to thank the children and their families for taking part in this study.

\section{REFERENCES}

1. Silverman M, Wilson NM. Wheezing disorders in infancy. In: Silverman M (ed). Childhood Asthma and Other Wheezing Disorders. London: Chapman and Hall Medical, 1995: 141-147.

2. Shalowitz MU, Mijanovich T, Berry CA, Clark-Kauffman E, Quinn KA, Perez EL. Context matters: a communitybased study of maternal mental health, life stressors, social support, and children's asthma. Pediatrics 2006; 117: 940-948.

3. Shalowitz MU, Berry CA, Quinn KA, Wolf RL. The relationship of life stressors and maternal depression to pediatric asthma morbidity in a subspecialty practice. Ambul Pediatr 2001; 1: 185-193.

4. Martinez KG, Pèrez EA, Ramirez R, Canino G, Rand C. The role of caregivers' depressive symptoms and asthma beliefs on asthma outcomes among low-income Puerto Rican children. J Asthma 2009; 46: 136-141.

5. Bartlett SJ, Krishnan JA, Riekert KA, Butz AM, Malveaux FJ, Rand CS. Maternal depressive symptoms and adherence to therapy in inner-city children with asthma. Pediatrics 2004; 113: 229-237.

6. Sales J, Fivush R, Teague GW. The role of parental coping in children with asthma's psychological wellbeing and asthma-related quality of life. J Pediatr Psychol 2008; 33: 208-219. 
7. Wright RJ, Cohen S, Carey V, Weiss ST, Gold DR. Parental stress as a predictor of wheezing in infancy: a prospective birth-cohort study. Am J Respir Crit Care Med 2002: 165: 358-365.

8. Wright RJ, Rodriguez M, Cohen S. Review of psychosocial stress and asthma: an integrated biopsychosocial approach. Thorax 1998; 53: 1066-1074.

9. Cohen S, Doyle WJ, Skoner DP. Psychological stress, cytokine production, and severity of upper respiratory illness. Psychosom Med 1999; 61: 175-180.

10. Cohen S, Frank E, Doyle WJ, Skoner DP, Rabin BS, Gwaltney JM Jr. Types of stressors that increase susceptibility to the common cold in adults. Health Psychol 1998; 17: 214-223.

11. Clover RD, Abell T, Becker LA, Crawford S, Ramsey $\mathrm{CN}$ Jr. Family functioning and stress as predictors of influenza B infection. J Fam Pract 1989; 28: 535-539.

12. Boyce WT, Chesney M, Alkon A, et al. Psychobiological reactivity to stress and childhood respiratory illnesses: results of two prospective studies. Psychosom Med 1995; 57: 411-422.

13. Giallo R, Bahreinian S, Brown S, Cooklin A, Kingston D, Kozyrskyj A. Maternal depressive symptoms across early childhood and asthma in school children: findings from a longitudinal Australian Population Based Study. PLoS One 2015; 10: e0121459.

14. Kozyrskyj AL, Mai XM, McGrath P, Hayglass KT, Becker $\mathrm{AB}$, Macneil B. Continued exposure to maternal distress in early life is associated with an increased risk of childhood asthma. Am J Respir Crit Care Med 2008: 177: $142-147$.

15. Hisli N. Beck Depresyon Envanteri'nin üniversite öğrencileri için geçerliği, güvenirliği. Türk Psikoloji Dergisi 1989; 7: 3-13.

16. Been JV, Lugtenberg MJ, Smets E, et al. Preterm birth and childhood wheezing disorders: a systematic review and meta-analysis. PLoS Med 2014 28; 11: e1001596.

17. Fogaça HR, Marson FA, Toro AA, Solé D, Ribeiro JD. Epidemiological aspects of and risk factors for wheezing in the first year of life. J Bras Pneumol 2014; 40: 617-625.

18. Sherriff A, Peters TJ, Henderson J, Strachan D; ALSPAC Study Team. Avon Longitudinal Study of Parents and Children. Risk factor associations with wheezing patterns in children followed longitudinally from birth to 3(1/2) years. Int J Epidemiol 2001; 30: 1473-1484.

19. Bueso A, Figueroa M, Cousin L, et al. Poverty-associated risk factors for wheezing in the first year of life in Honduras and El Salvador. Allergol Immunopathol (Madr) 2010; 38: 203-212.

20. Baker D, Taylor H, Henderson J. Inequality in infant morbidity: causes and consequences in England in the 1990 s. ALSPAC Study Team. Avon Longitudinal Study of Pregnancy and Childhood. J Epidemiol Community Health 1998; 52: 451-458.

21. Moraes LS, Takano OA, Mallol J, Solé D. Risk factors associated with wheezing in infants. J Pediatr (Rio J) 2013; 89: 559-566.

22. Mallol J, Solé D, Garcia-Marcos L, et al; EISL Latin American Group. Prevalence, severity, and treatment of recurrent wheezing during the first year of life: A cross-sectional study of 12,405 Latin American Infants. Allergy Asthma Immunol Res 2016; 8: 22-31.

23. Knafl K, Zoeller L. Childhood chronic illness: A comparison of mothers' and fathers' experiences. J Fam Nurs 2000; 6: 287-302.

24. van Oers HA, Haverman L, Limperg PF, van DijkLokkart EM, Maurice-Stam H, Grootenhuis MA. Anxiety and depression in mothers and fathers of a chronically ill child. Matern Child Health J 2014; 18: 1993-2002.

25. Im YJ, Park ES, Oh WO, Suk MH. Parenting and relationship characteristics in mothers with their children having atopic disease. J Child Health Care 2014; 18: 215-229.

26. Wright RJ, Cohen S, Carey V, Weiss ST, Gold DR. Parental stress as a predictor of wheezing in infancy: a prospective birth-cohort study. Am J Respir Crit Care Med 2002; 165: 358-365.

27. Gustafsson PA, Björkstèn B, Kjellman NI. Family dysfunction in asthma: a prospective study of illness development. J Pediatr 1994; 125: 493-498.

28. Lefevre F, Moreau D, Sèmon E, Kalaboka S, AnnesiMaesano I, Just J. Maternal depression related to infant's wheezing. Pediatr Allergy Immunol 2011; 22: 608-613.

29. Cookson H, Granell R, Joinson C, Ben-Shlomo Y, Henderson AJ. Mothers' anxiety during pregnancy is associated with asthma in their children. J Allergy Clin Immunol 2009; 123: 847-853.

30. Kozyrskyj AL, Mai XM, McGrath P, Hayglass KT, Becker $\mathrm{AB}$, Macneil B. Continued exposure to maternal distress in early life is associated with an increased risk of childhood asthma. Am J Respir Crit Care Med 2008; 177: 142-147.

31. Reyes M, Perzanowski MS, Whyatt RM, et al. Relationship between maternal demoralization, wheeze, and immunoglobulin E among inner-city children. Ann Allergy Asthma Immunol 2011; 107: 42-49.e1.

32. Guxens M, Sonnenschein-van der Voort Am, Tiemeier $\mathrm{H}$, et al. Parental psychological distress during pregnancy and wheezing in preschool children: The Generation R Study. J Allergy Clin Immunol 2014; 133: 59-67. e1-12.

33. Alton ME, Zeng Y, Tough SC, Mandhane PJ, Kozyrskyj AL. Postpartum depression, a direct and mediating risk factor for preschool wheeze in girls. Pediatr Pulmonol 2015; 51: 349-357.

34. van de Loo KF, van Gelder MM, Roukema J, Roeleveld N, Merkus PJ, Verhaak CM. Prenatal maternal psychological stress and childhood asthma and wheezing: A meta-analysis. Eur Respir J 2016; 47: 133-146.

35. Heneghan AM, Silver EJ, Bauman LJ, Westbrook LE, Stein RE. Depressive symptoms in inner-city mothers of young children: Who is at risk? Pediatrics 1998; 102: 1394-1400.

36. Horwitz SM, Briggs-Gowan MJ, Storfer-Isser A, Carter AS. Persistence of maternal depressive symptoms throughout the early years of childhood. J Womens Health (Larchmt) 2009; 18: 637-645. 
37. Chaplin TM, Aldao A. Gender differences in emotion expression in children: A meta-analytic review. Psychol Bull 2013; 139: 735-765.

38. Beeghly M, Partridge T, Tronick E, et al. Associations between early maternal depressive symptom trajectories and toddlers' felt security at 18 months: Are boys and girls at differential risk? Infant Ment Health J 2017; 38: 53-67.

39. Parry GD, Cooper CL, Moore JM, et al. Cognitive behavioral intervention for adults with anxiety complications of asthma: Prospective randomised trial. Respir Med 2012; 106: 802-810.
40. Marriage D, Henderson J. Cognitive behavior therapy for anxiety in children with asthma. Nurs Child Young People 2012; 24: 30-34.

41. Perry CD. Does treating maternal depression improve child health management? The case of pediatric asthma. J Health Econ 2008; 27: 157-173.

42. Heneghan AM, Silver EJ, Bauman LJ, Stein RE. Do pediatricians recognize mothers with depressive symptoms? Pediatrics 2000; 106: 1367-1373. 